\title{
Ligand-free estrogen receptor activity complements IGF1R to induce the proliferation of the MCF-7 breast cancer cells
}

\author{
Anne-Marie Gaben ${ }^{1,2^{*}}$, Michèle Sabbah ${ }^{1,2}$, Gérard Redeuilh ${ }^{1,2}$, Monique Bedin ${ }^{1,2}$ and Jan Mester ${ }^{1,2}$
}

\begin{abstract}
Background: Ligand-dependent activation of the estrogen receptor (ER) as well as of the insulin-like growth factor type 1 (IGF1R) induces the proliferation of luminal breast cancer cells. These two pathways cooperate and are interdependent. We addressed the question of the mechanisms of crosstalk between the ER and IGF1R.

Methods: We evaluated the mitogenic effects of estradiol (E2; agonist ligand of ER) and of insulin (a ligand of IGF1R) in the MCF-7 cells by flow cytometry and by analyzing the cell levels of cell cycle-related proteins (immunoblotting) and mRNA (RT-QPCR). To verify the requirement for the kinase activity of Akt (a downstream target of IGF1R) in the mitogenic action of estradiol, we used shRNA strategy and shRNA-resistant expression vectors.

Results: The activation of the ER by E2 is unable to induce the cell cycle progression when the phosphatidyl inositol-3 kinase (PI3K)/Akt signaling is blocked by a chemical inhibitor (LY 294002) or by shRNA targeting Akt1 and Akt2. shRNA-resistant Akt wild-type constructs efficiently complemented the mitogenic signaling activity of E2 whereas constructs with inactivated kinase function did not. In growth factor-starved cells, the residual PI3K/Akt activity is sufficient to complement the mitogenic action of E2. Conversely, when ER function is blocked by the antiestrogen ICI 182780, IGF1R signaling is intact but does not lead to efficient reinitiation of the cell cycle in quiescent, growth factor-starved MCF-7 cells. The basal transcription-promoting activity of ligand-free ER in growth factor-starved cells is sufficient to complement the mitogenic action of the IGF1R-dependent signaling.

Conclusions: The basal ER activity in the absence of ligand is sufficient to allow efficient mitogenic action of IGF1R agonists and needs to be blocked to prevent the cell cycle progression.
\end{abstract}

\section{Background}

Therapies based on hormonal manipulations are routinely applied in breast cancer patients whose tumors express estrogen receptor $\alpha$ (ER) ("luminal breast cancer", some $75-80 \%$ of all breast cancers); of these, some $50 \%$ benefit from objective responses. The current methods use the inhibition of action of endogenous estrogens by selective estrogen receptor modulators (SERM) such as tamoxifen, or by the suppression of endogenous estrogen production by aromatase inhibitors [1,2].

The primary lack of sensitivity to these therapies of a subset of luminal tumors, as well as the secondary

\footnotetext{
* Correspondence: anne-marie.gaben@inserm.fr

IInserm U938, Centre de Recherche Saint-Antoine, Hôpital Saint-Antoine, Bâtiment Kourilsky, 34 rue Crozatier, 75571, Paris cedex 12, France

${ }^{2}$ Université Pierre-et-Marie-Curie Paris 6, 75005, Paris, France
}

resistance which sets in after an initial response, prevent the cure of patients from their cancer by hormonal therapy alone. There has been extensive speculation concerning the mechanisms of resistance. Activating ER mutations or cyclic AMP-dependent phosphorylation [3] account only for a small fraction of relapses. The majority of relapses of breast cancer under hormone therapy probably results from alternative mitogenic pathways triggered by polypeptide growth factors (HER family and IGF) whose actions are transmitted by membrane receptors [4-6]. These pathways have their own impact on cell survival and proliferation but can also phosphorylate the ER (and/or the appropriate transcriptional co-activators) and reinforce its activity. Laboratory research using breast cancer-derived cell lines produced abundant information concerning mitogenic signaling pathways 
dependent on estrogens as well as on polypeptide growth factors. However, the data presented by different research groups are sometimes contradictory. In particular, the action of estrogens has been reported to be mediated by direct transcription-promoting activity of the ER [7] or by activation of kinase cascades identical to those triggered by cell surface receptors of polypeptide growth factors [8]. Data obtained in our laboratory [9] argue in favor of the direct transcriptional mechanism, but nonetheless confirm the fact that inhibition of the PI3K/Akt cascade by chemical inhibitors or by shRNA prevents the mitogenic activity of estradiol in the MCF-7 cells. The importance of PI3K activity in the IGF-I-induced mitogenic signaling in the MCF-7 cells has been reported by Dufourny et al. [10]. Similarly, although to a lesser extent, the inhibition of the MEK/ERK pathway reduces the mitogenic activity of estradiol (E2). Conversely, it has been reported that the mitogenic activity of IGF1R is blocked by ICI 182780 $[11,12]$; this anti-estrogen belongs to the category of selective estrogen receptor down-regulators (SERD) since its presence in the cell culture medium leads to a substantial decrease in the content of ER [13]. These data suggest the importance of crosstalk between the signaling by ER and by growth factor receptors.

In this work we have addressed two questions: first, the requirement of the PI3K activity and in particular of the kinase function of its downstream mediator Akt in the estrogen-induced cell cycle progression, and second, the interplay between the ER- and IGF1R-dependent mitogenic signaling pathways.

\section{Methods}

\section{Cell culture}

Breast cancer-derived cell lines (MCF-7, MELN) were propagated in DMEM supplemented with $10 \%$ fetal bovine serum (FBS).

For experiments, the cells were seeded at approximately $20.10^{3} / \mathrm{cm}^{2}$, allowed to attach overnight, washed twice and placed in phenol red-free, serum- free DMEM containing or not $10 \mathrm{nM}$ ICI 182780 for various times as indicated. Mitogenic stimulation was carried out by pipetting the reagents directly into the culture medium in the dish to produce final concentrations: $1 \mu \mathrm{M}$ estradiol (100-fold excess over the antiestrogen) or $1 \mu \mathrm{M}$ insulin (sufficient to activate the IGF1R), or $10 \mathrm{nM}$ IGF-I. The final concentrations of other drugs used in some experiments were $20 \mu \mathrm{M}$ for LY 294002 and $10 \mu \mathrm{g} / \mathrm{mL}$ for cycloheximide.

The distribution of cells among the phases of the cell cycle was evaluated by staining with propidium iodide and flow cytometry.

\section{Expression vectors and shRNA}

The shRNA Akt $(1+2)$ vector was a gift of Dr. F. Czauderna. It contains a sequence (cloned under pol III promoter in a U6 vector) common to isoforms of Akt1 and Akt2 [14].

The effective and specific suppression of Akt expression by this sequence in the HeLa cells has been verified by these authors and we have confirmed this suppression in the MCF-7 cells (Additional file 1: Figure S1).

To create wild-type Akt1 (Akt1R) and Akt2 (Akt2R) vectors, resistant to shRNA Akt $(1+2)$, we used the HAAkt1 and HA-Akt2 expression vectors (obtained from Xiao GH, Altomare DA and Testa JR, Fox Chase Cancer, Philadelphia, USA) [15]. We introduced silent mutations of 3 codons within the shRNA target common sequence. The following sequences were used: Akt1, forward 5' CCAACACCTTCATCATCCggTgTCTCCAgTggACCAC TgTCATCg-3'; reverse 5' -CgATgACAgTggTCCACTggA gACACCggATgATgAAggTgTTgg-3' and Akt2, forward 5 ' -CCAACACCTTTgTCATACggTgTCTCCAgTggACC ACAgTCATCG-3'; reverse 5'-CgATgACTgTgTggTCCA CTggAgACACCgTATgACAAAggTgTTgg-3'.

To replace the endogenous Akt1 or Akt2 by kinasedead, sh-RNA-resistant variants, we introduced additional mutation substituting alanine for lysine at position 179 or 181 for Akt1 and Akt2 respectively in the catalytic domains of Akt1R and Akt2R kinases [16]. Point mutation was accomplished by PCR primer mutagens using the QuikChange II Site-Directed Mutagenesis Kit (Stratagene). The following sequences were used: Akt1R/KD (Kinase Dead), forward 5'-CgCTACTACgCCATggCgAT CCTCAAgAAgg-3'; reverse 5'-CCTTCTTgAggA TCgCCATggCgTAgTAgCg-3' and Akt2R/KD (Kinase dead), forward 5'-CgCTAC TACgCCATggCgATCCTgCg AAAgg-3'; reverse 5' -CCTTTCgCAggATCgCCATggCgT Ag TAgCg-3'.

Control cells were transfected with the empty pcDNA3 vector. For each transfection, the total quantity of transfected plasmid DNA was completed to $2 \mu \mathrm{g}$ by the addition of pcDNA3 plasmid (Invitrogen, Life Technologies, Carlsbad, CA). The indicator plasmid used was pCA-Luc (luciferase cDNA cloned downstream of the cyclin A promoter) [17].

\section{Transfection experiments}

Cells were transfected with expression vectors containing: shRNA sequence complementary to Akt1 and Akt2 mRNA (shAkt1 + 2); shRNA-resistant Akt1 or Akt2 (Akt1R and Akt2R); shRNA-kinase dead Akt1 and Akt2 (Akt1R/KD and Akt2R/KD); cyclin A-luciferase (indicator of late G1 phase; $\beta$-galactosidase (indicator of transfection efficiency). Transfections were carried out by the Lipofectamine Plus method (Invitrogen) according to the manufacturer's protocol. After $3 \mathrm{~h}$ incubation with the DNA-containing liposomes, the cells were rinsed and incubated $40 \mathrm{~h}$ in serum-free, phenol red-free DMEM with $10 \mathrm{nM}$ ICI 182780 prior to stimulation 
with E2 for additional $24 \mathrm{~h}$. Cells were then lysed in Reporter Lysis Buffer (Promega) and the luciferase and $\beta$-galactosidase (Galacto-Star-Applied Biosystems) activities were determined.

\section{Western blotting}

Cells were harvested on ice in a Tris $(50 \mathrm{mM}, \mathrm{pH} 7.4)$ buffer containing EDTA (20 mM) Nonidet P-40 (0.5\%), $\mathrm{NaCl}$ (150 mM), dithiothreitol (1 mM), aprotinin (1 mg/ $\mathrm{mL})$, leupeptine $(1 \mathrm{mg} / \mathrm{mL})$, phenylmethylsulfonyl fluoride $(0.3 \mathrm{mM}), \mathrm{NaF}(1 \mathrm{mM})$, and sodium orthovanadate ( $1 \mathrm{mM})$. The lysates were clarified by centrifugation $(10,000 \times g$ for $5 \mathrm{~min})$. The total protein concentration was determined by Bio-Rad assay (Bio-Rad, Hercules, CA). $100 \mu \mathrm{g}$ of total protein were denaturated by boiling in Læmmli buffer containing sodium dodecyl sulfate (1\% final concentration) and 2-mercaptoethanol (100 mM) before fractionation by electrophoresis in a polyacrylamide gel $(8 \%$ or $10 \%$ as needed). The proteins were then electrotransferred onto a Hybond membrane and incubated with the appropriate antibodies followed by the peroxidase-tagged secondary antibody. The primary antibodies used were: from Cell Signaling Technology (Beverly, MA) for Akt, phospho-Ser473-Akt, IGF1R ( $\beta$ chain), phospho-GSK $3 \alpha / \beta$, p21 ${ }^{\mathrm{WAF} 1 / \mathrm{CIP} 1}$, cyclin $\mathrm{A}$; from Santa Cruz Biotechnology (Santa Cruz, CA, USA) for p27 (C-19); from Thermo Fisher Scientific Fremont, (CA, USA) for cyclin D1 (cyclin D1/bcl-1 Ab-1, clone DCS-6); from Millipore Corporation (Temecula, CA, USA) for phospho-ER; from BD Pharmingen (Le Pont de Claix, France) for Rb.

The detection of the signal was carried out with the enhanced chemoluminescence kit (Amersham Biosciences, Saclay, France.).

\section{mRNA quantification}

RNA was isolated by using Trizol (Euromedex). One microgram of total RNA was reverse transcribed with $200 \mathrm{ng}$ random primers (Invitrogen) and ImProm-II reverse transcriptase (Promega) for $60 \mathrm{~min}$ at $42^{\circ} \mathrm{C}$, in $20 \mu$ final volume.

The cDNA (equivalent of $0.2 \mu \mathrm{L}$ of the $\mathrm{RT}$ reaction mix) was subjected to Q-PCR using Sybr green (Applied Biosciences, Foster City, CA) and appropriate primers. The mRNA contents were evaluated based on the comparative $\triangle \mathrm{CT}$ method and normalized to the housekeeping gene 36B4 as described previously [18].

\section{Results}

To reduce the risk that experimental results may be influenced by cell heterogeneity, we subcloned MCF-7 cells by limiting dilution. All clones analyzed (18 in total) ceased to proliferate in serum- and estrogen-free medium, and responded to mitogenic stimulation by E2 and insulin. Four clones were further analyzed and found to express the ER and PR (inducible by E2). One of these clones was used in all subsequent experiments.

1. The kinase function of Akt is required for the E2-dependent cell cycle progression.

In our previous work we showed that depletion of Akt1 and 2 prevented the mitogenic signaling by $\mathrm{E} 2$ in the MCF-7 cells. At the same time, E2 stimulation failed to induce the activating phosphorylation of Akt on Ser 473. This opened the possibility that Akt may have a function unrelated to its kinase activity, as has been suggested in a different context $[16,19]$. We therefore produced Akt1 and Akt2 expression vectors carrying silent mutations in the sequence targeted by shRNA, as well as in the kinase domain. As reported by Nakatani et al. [20] and Zinda et al. [21], Akt3 is not expressed in the MCF-7 cells. We tested these constructs for their capacity to "rescue" the mitogenic action of E2 in cells exposed to shRNA targeting Akt1 and 2. The end-point was the activation of the promoter of the cyclin A gene cloned upstream of a luciferase coding sequence, as an indicator of late $\mathrm{G} 1$ phase.

When cells were transfected with the shRNAexpression vector Akt $(1+2)$ directed against a sequence shared by Akt1 and 2 mRNAs, the activation of the cyclin A promoter by E2 was blocked and co-transfection of expression vectors coding for shRNA-resistant, wild type kinase variants of the Akt isoforms (Akt1R, Akt2R) restored the cyclin A promoter activation as revealed by the induction of luciferase. Akt2 appeared to be more efficient to restore the full mitogenic effect of E2 than Akt1 (Figure 1A).

Next we compared the wild-type, shRNA-resistant Akt constructs with their kinase-dead counterparts Akt1R/KD and Akt2R/KD. In these experiments, the inclusion of the $K D$ variants resulted in a reduced transfection efficiency documented by the diminished activity of the indicator $\beta$-galactosidase. Therefore, we treated groups of dishes with E2 and kept other groups of dishes as controls (in the serum-free medium supplemented with ICI 182780), to calculate the induction factor for the luciferase/ $\beta$-galactosidase ratios. The results showed that with the kinase-dead mutants, there was only a partial restoration of luciferase induction (Figure 1B) as compared with the wild-type Akt2R used as a positive control. The results of these experiments 

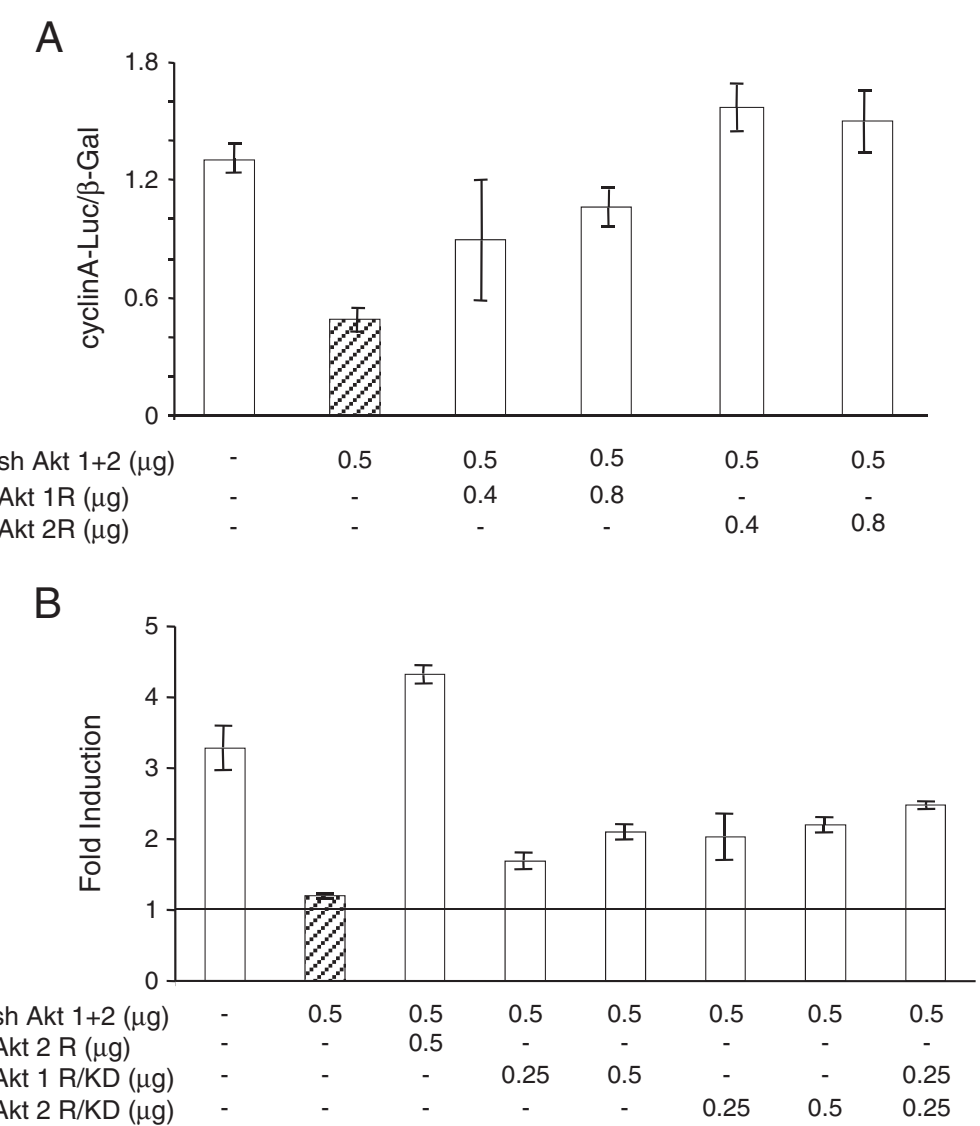

Figure 1 Akt kinase activity is required for the E2 -induced reinitiation of the cell cycle progression. A: MCF-7 cells seeded in $35 \mathrm{~mm}$ dishes were transfected with shRNA Akt $(1+2)(0.5 \mu \mathrm{g}$ per dish) together with expression vectors of shRNA-resistant mutants of Akt1 (Akt1R) or Akt2 (Akt2R) as indicated, and an indicator plasmid encoding luciferase cloned downstream of cyclin A promoter $(0.5 \mu \mathrm{g})$. A $\beta$-galactosidase vector $(100 \mathrm{ng})$ was included to allow the correction for transfection efficiency. For more details see Materials and Methods. The cells were lysed and the activity of luciferase and $\beta$-galactosidase were determined. The results shown are means and s.e.m. of triplicates. B: The cells were transfected as in A with shAkt $(1+2)$, Akt2R, or kinase-dead shRNA-resistant mutants of Akt1 (Akt1R/KD) or Akt2 (Akt2R/KD) as indicated. After transfection, the cells were made quiescent as in A. To a set of dishes of each transfection mix, E2 was added to a final concentration of $1 \mu \mathrm{M}$, the remaining dishes were left in the medium containing ICI 182780 (control). The data presented show the induction factor (E2 vs. control) calculated for the luciferase/ $\beta$-galactosidase activities. The results shown are means $+/-$ s.e.m. of triplicates.

demonstrate that the kinase function of exogenous Akt is required for efficient rescue of E2-inducible cell cycle progression when endogenous Akt is knocked down.

2. Cells deprived of serum in the absence of ICI 182780 continue to express cell cycle markers.

The arrest of proliferation by depriving the MCF-7 cells of exogenous mitogens was characterized by changes in the cell contents of certain markers of mitogenic signaling of the cell cycle (Figure 2).

Interruption of the mitogenic signaling is illustrated by the changes in the phosphorylation status of the $\mathrm{Rb}$ protein, a substrate of cyclin-dependent kinases and a modulator of late G1-phase gene expression.
After incubation for $24 \mathrm{~h}$ or longer in serum and phenol red-free medium containing ICI 182780, Rb was dephosphorylated, whereas a significant fraction of $\mathrm{Rb}$ remained phosphorylated when ICI 182780 was omitted. This indicates that the suppression of ER by the antiestrogen is required for an efficient block of the induction of cyclin-dependent kinases. This conclusion is also supported by the presence of a residual cyclin A in cells deprived of serum in the absence of the antiestrogen whereas in the presence of the antiestrogen, the cyclin A signal is nearly eliminated (Figure 2).

The cdk inhibitory proteins $\mathrm{p} 21^{\mathrm{WAF} 1 / \mathrm{CIP} 1}$ and $\mathrm{p} 27$ accumulated in cells deprived of serum. Whereas the addition of ICI 182780 in the starvation medium made no difference for $\mathrm{p} 27$, it led to a strongly 


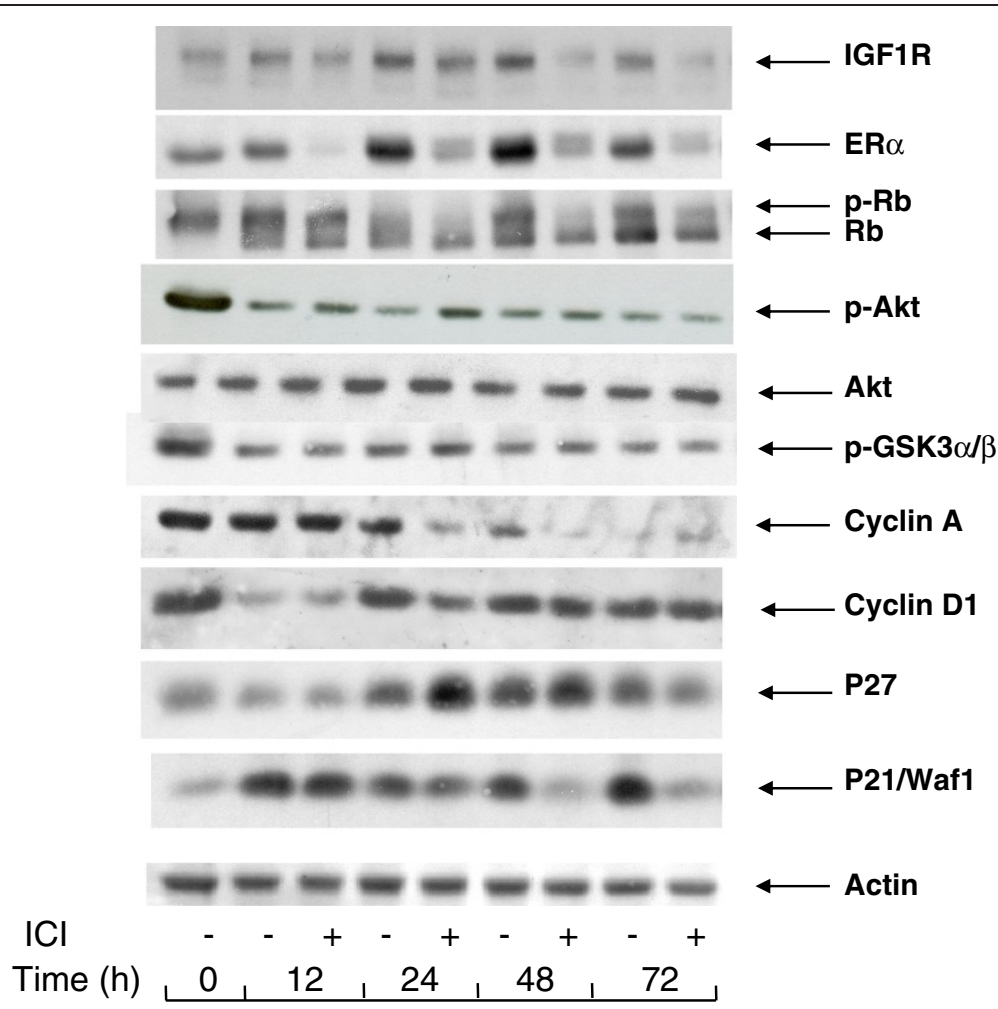

Figure 2 Changes in the levels of cell cycle-related and signaling proteins during serum- and E2 -starvation. MCF-7 cells were seeded in $60 \mathrm{~mm}$ dishes and allowed to attach overnight. They were then placed in serum- and phenol red-free medium containing or not $10 \mathrm{nM} \mathrm{ICl}$ 182780 for periods of time as indicated. After lysis, the different proteins were revealed by Western blotting with the appropriate antibodies.

reduced cell content of p21 WAF1/CIP1 after a transient increase seen at $12 \mathrm{~h}$ (Figure 2). The expression of IGF1R also showed a slightly higher level in cells deprived of serum in a medium without the antiestrogen. As the suppression of ER by ICI 182780 leads to a reduced expression of certain genes (see below, section 6), it is likely that the levels of their protein products result from the basal transcription-regulating activity of ligand-free ER.

As expected, in the cells serum-starved in medium with ICI 182780, ER was rapidly eliminated, the signal being near absent at $12 \mathrm{~h}$. In spite of the continued presence of ICI 182780, ER became again detectable at later times. Starvation of serum and E2 in the absence of the antiestrogen led to a progressive accumulation of ER, as seen between 24 and $72 \mathrm{~h}$.

It is to be noted that the cell contents of cyclin D1, a marker of early G1 phase, showed an early decrease at $12 \mathrm{~h}$ but then regained about the initial level and remained approximately constant throughout the $72 \mathrm{~h}$ incubation in serum-free medium. The presence of ICI 182780 did not reduce the level of cyclin D1 in mitogen-deprived cells (Figure 2).

3. Serum and estrogen deprivation does not eliminate phospho-Akt.

Since the presence of the wild-type form of Akt is a prerequisite for the mitogenic signaling by E2 and since E2 does not induce the activating phosphorylation of Akt, we set out to verify by Western blotting the presence of phospho-Ser473Akt (p-Akt) in the MCF-7 cells incubated in serum and estrogen-free medium. In these experiments the intensity of the p-Akt signal became weaker during serum deprivation but remained detectable, whether the cells had been incubated in a medium deprived of serum and exogenous estrogens, or in the same medium supplemented with ICI 182780. GSK3 $\alpha / \beta$ a substrate of Akt kinase, showed a similar profile of phosphorylation (Figure 2).

In order to verify that the signal detected with the anti-P-Ser473-Akt antibody represented the phosphorylated Akt rather than a non-specific antigen co-migrating incidentally with Akt, we 
treated the cell lysates with phosphatase. This treatment abolished the p-Akt signal both in cell lysates prepared from the quiescent MCF-7 cells and in cells treated for $1 \mathrm{~h}$ with insulin, a powerful inducer of the PI3K/Akt signaling (see Additional file 2: Figure S2).

The phosphorylation of Akt in the quiescent MCF-7 cells could be a consequence of signaling by an autocrine factor. To test this possibility, we harvested conditioned medium from cells after $48 \mathrm{~h}$ of incubation in the absence of serum and we compared the phosphorylation of Akt in quiescent cells placed in fresh DMEM with that detected in cells incubated with the conditioned medium. No difference was seen, suggesting that the Akt phosphorylation resulted from endogenous mechanisms and was not mediated by a secreted autocrine factor (see Additional file 3: Figure S3).

4. IGF1R signal transduction is not sufficient to drive the $\mathrm{G} 1$ phase progression.

Stimulation of the IGF1R signaling pathway induces a rapid and lasting phosphorylation of Akt. IGF-I and -II, as well as insulin at supra-physiological concentrations, are efficient mitogens in estrogendeprived MCF-7 cells. Also, simultaneous stimulation of this pathway and of the ER acts in synergy to induce the MCF-7 cells' proliferation. It has been reported by the laboratory of R. Sutherland that suppression of ER-dependent signaling by ICI 182780 prevents the mitogenic activity of insulin in these cells whereas antiestrogens of the type "SERM" do not show this effect [22]. Varma and Conrad [12] showed that the direct effects of IGF, phosphorylation of IGF1R and of Akt, are unaffected by ICI 182780, in contrast with the inhibition of the mitogenic action. We have addressed the mechanisms underlying the cooperation of the ER and IGF1R pathways. We analyzed the effects of E2 and insulin on the distribution of cells among the phases of the cell division cycle (Figure 3; Additional file 4: Figure S4). Remarkably, even after $48 \mathrm{~h}$ incubation in serum-free medium, the MCF-7 cells did not become fully quiescent, with approximately $20 \%$ of the total population in S+G2/M-phase (Figure 3, time 0, lower panel). If the serum-free culture medium contained ICI 182780, after $48 \mathrm{~h}$ there remained practically no $\mathrm{S}+\mathrm{G} 2 / \mathrm{M}$-phase cells. Stimulation with E2 or with insulin triggered the re-entry of G0/G1 arrested cells into the cell division cycle (Figure 3). The most marked mitogenic effect was seen when the cells were fully synchronized by serum-starvation in the presence of ICI 182780 and subsequently stimulated by the addition of E2 (100fold excess over ICI 182780). In these conditions, insulin produced only a weak and delayed effect. In contrast, insulin was an efficient mitogen when ICI 182780 was omitted from the culture medium (Figure 3, lower panel).

These data confirm that pretreatment of the MCF-7 cells with ICI 182780 strongly reduces their sensitivity to the mitogenic action of insulin (Figure 3) while the signal transduction by IGF1R is intact as documented by the strong induction of Akt phosphorylation by insulin in such cells, similar to that seen in cells deprived of serum in the absence of the antiestrogen (Figure 4, upper panel). We also observed an induction of cyclin D1 in cells starved of serum with and without ICI 182780, confirming that this process reflects direct IGFR1 signaling and is not sufficient for the cell cycle progression. There was though a correlation between the induction of cyclin D1 accumulation and the mitogenic action as shown by the FACS data: stronger induction by E2, weaker by insulin in antiestrogen-exposed cells.

The fact that chemical inhibitors of PI3K block the mitogenic signaling in breast cancer cells has been reported earlier $[9,23]$. This is also illustrated by the effect of LY 294002 on the expression of cyclin A (Figure 4, upper panel). In cells starved of mitogens in a medium without antiestrogen, cyclin $\mathrm{A}$ remained detectable, and its content did not diminish during a short ( 3 to $6 \mathrm{~h}$ ) incubation with LY 294002 (Figure 4, upper panel). The expression of cyclin A in these conditions is probably the consequence of the incomplete quiescence (Figure 3). When the cells were stimulated with E2 or with insulin for $19 \mathrm{~h}$ (late G1 phase), cyclin A was strongly induced and this induction was abolished by LY 294002 (Figure 4, lower panel).

As expected, the effect of IGF-I (10 nM) was the same as that of insulin $(1 \mu \mathrm{M})$ (Additional file 5 : Figure S5).

As ICI 182780 is a SERD-type antiestrogen (inducer of ER degradation), the lack of ER after pretreatment with this compound could be a reason for the diminished sensitivity of the cells to insulin. This is however unlikely to be the case as the reinitiation of the cell cycle progression by E2 in ICI 182780pretreated cells is actually stronger than that of cells not pretreated with the antiestrogen, in spite of the 

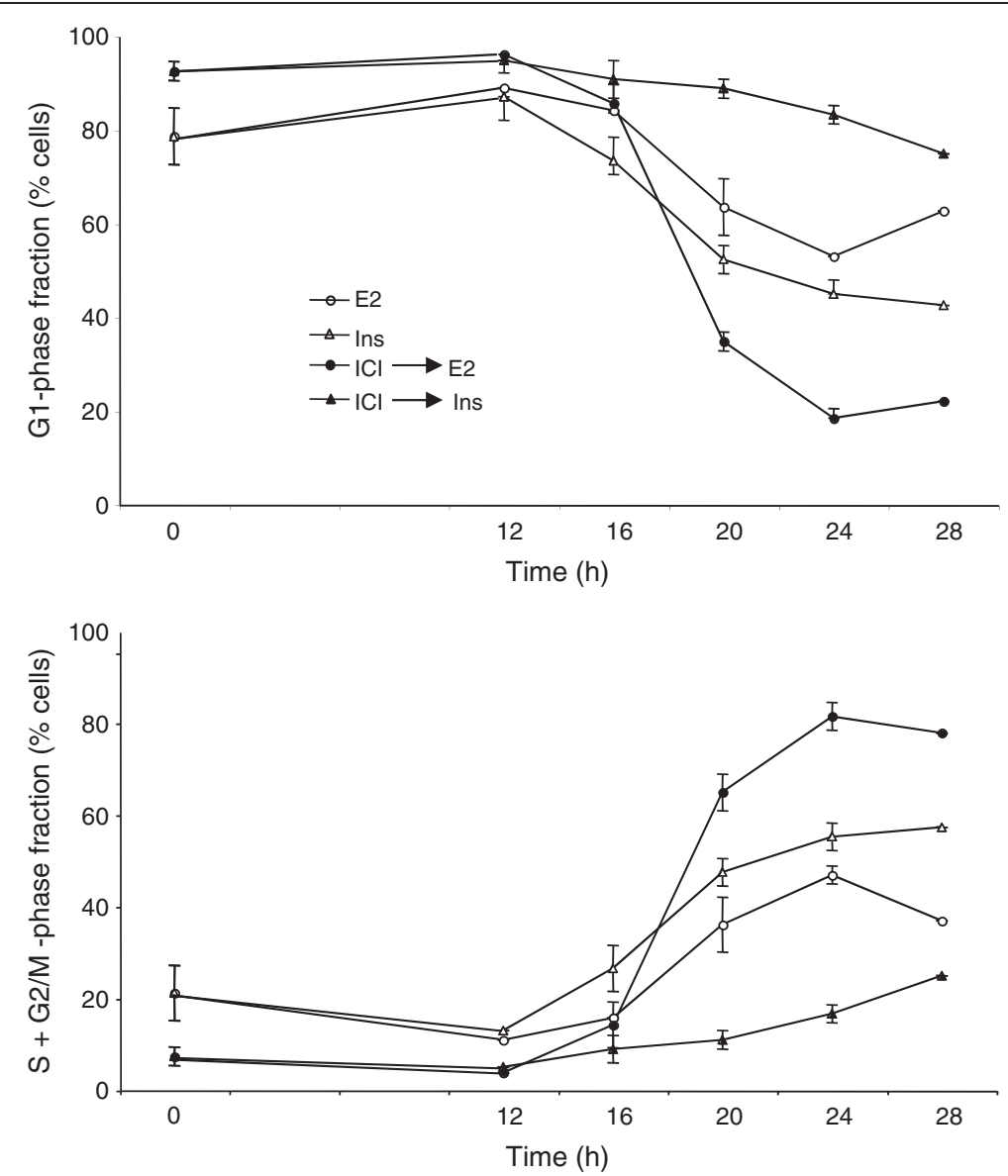

Figure 3 Reinitiation of the cell cycle progression in quiescent cells. Blocking the ER function inhibits the insulin-induced reinitiation of the cell cycle progression. MCF-7 cells were placed in serum- and phenol red-free medium containing or not $10 \mathrm{nM} I \mathrm{Cl} 182780 \mathrm{for} 48 \mathrm{~h}$. Subsequently the cells were stimulated by addition of insulin $(\mathrm{Ins} ; 1 \mu \mathrm{M})$ or E2 $(1 \mu \mathrm{M})$. The cells were harvested for analysis of their DNA contents by flow cytometry at $\mathrm{t}=0,12,16,20,24$ and $28 \mathrm{~h}$ as shown. The data (means of 2 to 4 experiments) are plotted as percent of cells in the G1 phase and S phase. S.e.m. are shown (unless smaller than the size of the symbol).

strong reduction of the cell contents in ER

(Figure 2). The recent report of Wardell et al. [24] demonstrates that the efficacy of ICI 182780 as an antiestrogen does not rely on its ability to induce $\mathrm{ER} \alpha$ degradation.

5. Effect of the suppression of the PI3K pathway on the expression of cyclin D1 and c-myc protein and mRNA.

We were intrigued by the continuous presence of cyclin D1 in serum- and estrogen-deprived cells, non-suppressible by long-term treatment with ICI 182780. Signaling by the PI3K/Akt pathway favors the accumulation of the cyclin D1 protein by posttranscriptional mechanisms: accelerated translation $[25,26]$ as well as inhibition of degradation of the cyclin D1 protein due to the inhibition of GSK3 $\alpha / \beta$ through phosphorylation by Akt [27].
In order to verify the role of the basal level of phosphorylated Akt in the expression of cyclin D1, we examined the effect of the PI3K inhibitor LY 294002. A $3 \mathrm{~h}$ incubation of serum-deprived cells with this drug strongly reduced the p-Akt signal, indicating that the basal phosphorylation of Akt seen in mitogen-deprived cells depended on PI3K activity. Further, our experiments showed a strong inhibition of the basal cyclin D1 expression by a $3 \mathrm{~h}$ exposure of the cells to LY 294002 (Figure 4, upper panel, $t=0$ ). The presence of LY294002 led to a reduction of the contents in cyclin D1 also when the cells were stimulated with either insulin or E2 (Figure 4, upper panel). Next we examined the transcriptional regulation of the CCND1 gene (Figure 5). The presence of ICI 182780 during serum deprivation did not modify the level of cyclin D1 mRNA. After $48 \mathrm{~h}$ in serum-free medium, an incubation for $3 \mathrm{~h}$ with $20 \mu \mathrm{M}$ LY294002 led to a 2 to 3 -fold decrease 


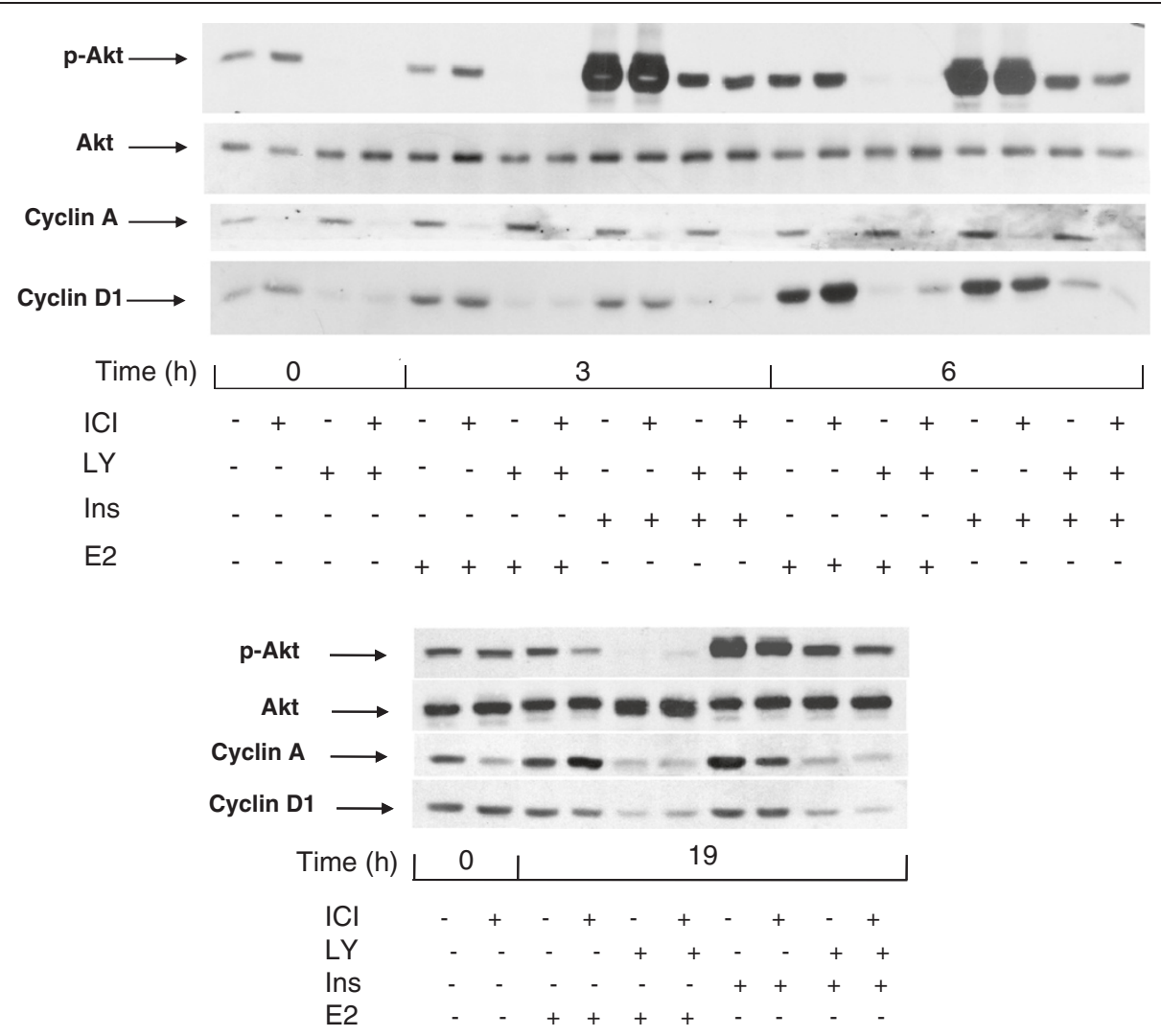

Figure 4 Effect of the inhibition of PI3K by LY 294002 on the induction of cyclins D1 and A. MCF-7 cells were starved of serum and E2 during $48 \mathrm{~h}$ in the presence or absence of ICl 182780 (10 nM). Last 3 hours of serum deprivation (time $-3 \mathrm{~h}$ to $0 \mathrm{~h}$ ), one series of dishes was treated with $L Y 294002(L Y ; 20 \mu M)$. Subsequently, at $t=0$, all cells were stimulated by the addition of insulin (ins; $1 \mu \mathrm{M})$ or $E 2(1 \mu \mathrm{M})$ for $3 \mathrm{~h}$ or $6 \mathrm{~h}$ (upper panel) or $19 \mathrm{~h}$ (lower panel). After lysis, the different proteins were revealed by after Western blotting using specific antibodies.

of cyclin D1 mRNA contents, indicating that the basal activity of PI3K was required to maintain the expression of the CCND1 gene (Figure 5, bars 3, 4 vs. 1, 2). Stimulation of the quiescent cells with either E2 or insulin induced the accumulation of cyclin D1 mRNA (about 3-fold at $4 \mathrm{~h}$ ). The amplitude of this induction paralleled the pattern of reinitiation of the cell cycle progression (Figure 3): insulin was more efficient when serum deprivation had been carried out without ICI 182780 (Figure 5, bar 5 vs. 6), whereas the effect of E2 was more marked in cells rendered quiescent in the presence of ICI 182780 (bar 9 vs. 10). The induction of cyclin D1 mRNA by E2 was not prevented by LY 294002 (about 3-fold at $4 \mathrm{~h}$ compared with the level in control, LY 294002exposed cells; Figure 5); although the absolute level was lower than that reached without LY 294002, the induction of CCND1 transcription by estradiol apparently proceeded unhindered (compare bars 3 vs. 11 and 4 vs. 12; differences significant at respectively $\mathrm{p} \leq 0.05$ and $\mathrm{p} \leq 0.01$ ). On the other hand, the induction of the expression of the CCND1 gene by insulin was efficiently inhibited by LY294002.

In contrast, in cells cultured in serum-free medium, a $3 \mathrm{~h}$ exposure to LY 294002 did not affect the level of the c-myc mRNA (Figure 5, bars 1 vs. 3 and 2 vs. 4). The same result was noted when the cells were stimulated with insulin (absence of effect of LY 294002; bars 5 vs. 7 and 6 vs. 8). The induction of c-myc mRNA accumulation by E2 was actually increased by LY294002 (difference significant for cells maintained without ICI 182780; bars 9 vs. 11, $\mathrm{p} \leq 0.01)$. It is to be noted that ICI 182780 prevented the induction of c-myc mRNA accumulation by insulin (Figure 5, compare bars 5 vs. 6 and 7 vs. 8).

6. Transcriptional activity of unliganded ER in serumdeprived MCF-7 cells.

The essential consequence of the presence of ICI 182780 is the suppression of the basal level of 


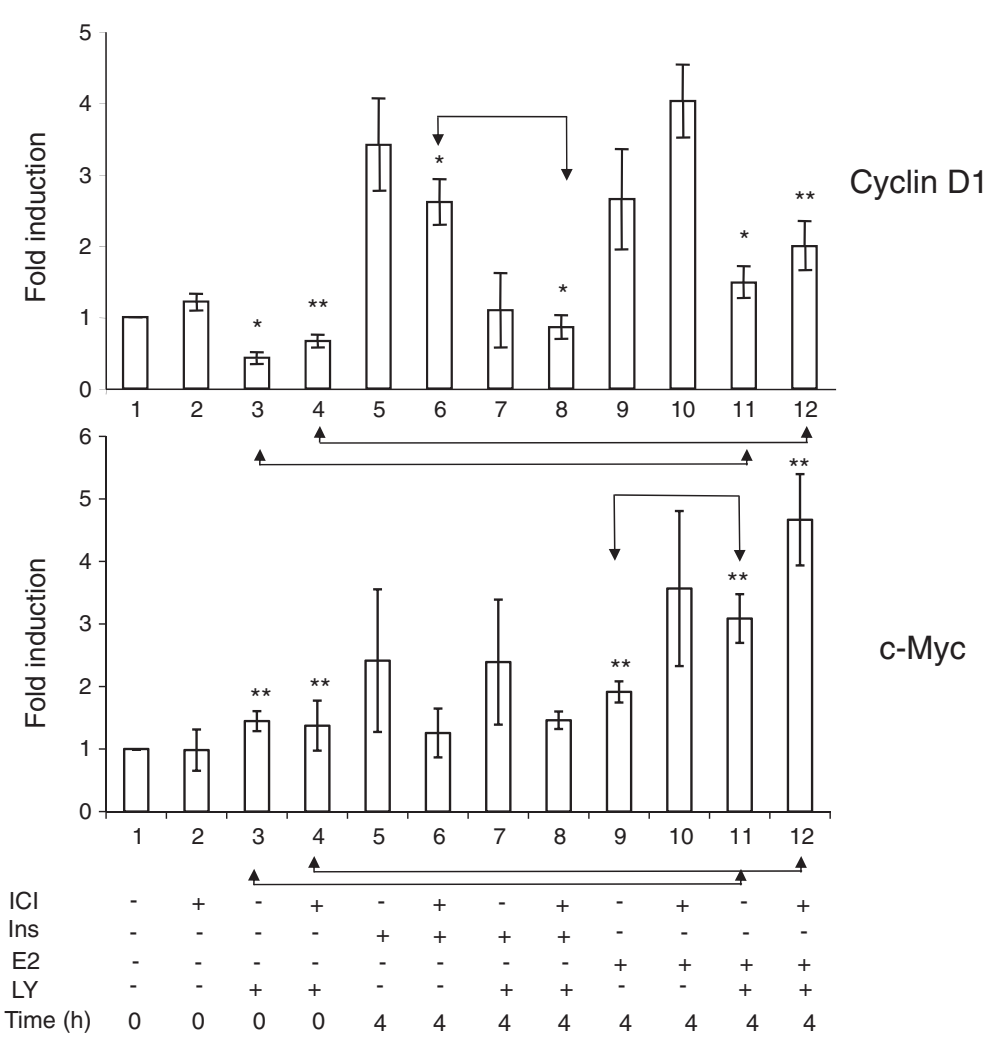

Figure 5 Effect of LY 294002 on the induction of cyclin D1 and c-myc mRNA. MCF-7 cells were starved of serum and E2, in the presence or absence of ICl 182780, for $48 \mathrm{~h}$. In one series of dishes, LY294002 was added for the last $3 \mathrm{~h}$ of serum deprivation (time $-3 \mathrm{~h}$ to $0 \mathrm{~h}$ ). The cells were then stimulated with E2 $(1 \mu \mathrm{M})$ or insulin $(1 \mu \mathrm{M})$ for $4 \mathrm{~h}$. The cells were then harvested for the isolation of RNA and RT-QPCR analysis. Fold induction of $\Delta \Delta C T$ (means of three independent experiments performed in triplicate) related to the values at $t=0$ in cells starved of serum in the absence of $\mathrm{ICl} 182780$, are presented. The differences between bars 3 vs 11, 4 vs 12,6 vs 8 and 9 vs 11 are significant at $p \leq 0.05\left({ }^{*}\right)$ or $\left.p \leq 0.01 * *\right)$.

ER-dependent gene expression. This was documented by monitoring the levels of two transcripts encoded by genes with estrogen response elements in their promoters, $p S 2$ and $P R$ (progesterone receptor). ICI 182780 caused a strong decrease in the expression of these genes (by approximately $90 \%$ after $48 \mathrm{~h}$ ) whereas in the absence of the antiestrogen their mRNA levels decreased respectively by approximately $50 \%$ as compared to those observed in the exponential cells (Figure 6).

In order to obtain a more direct information about the ER-dependent transcription in the absence of ligand, we evaluated the expression of luciferase in the MELN cell line derived from the MCF-7 cells by stable transfection with ERE-TK-LUC [28]. When placed in serum- and phenol red-free medium, the cell content in luciferase varied little, whereas the addition of ICI 182780 led to a rapid extinction of the indicator enzyme, at a rate similar to that caused by the protein synthesis inhibitor cycloheximide, after a delay of about $3 \mathrm{~h}$ (Figure 7A). This delay is understandable: cycloheximide blocks all de novo synthesis of luciferase protein whereas ICI 182780 prevents the synthesis of mRNA coding for luciferase and not the translation of pre-existing mRNA. To ascertain that the continued expression of luciferase was not due to a possible residual estrogen, we cultured the MELN cells for more than a month (a minimum of 4 passages) in estrogen-free medium supplemented with charcoal-stripped serum plus $100 \mathrm{nM}$ Insulin. The cells were then placed in serum-free medium, without insulin, with or without ICI 182780. Similar results were obtained: ICI 182780 rapidly extinguished the expression of luciferase whereas in the absence of the antiestrogen the level of luciferase increased with time (Figure 7B)

A possible explanation of these results is the existence of pathways that lead to the phosphorylation of the ER and of co-activators that participate at the regulation of its transcriptional activity. This possibility is sustained by the fact that phospho-Ser118-ER is detected in the serumdeprived MCF-7 cells (data not shown). The 


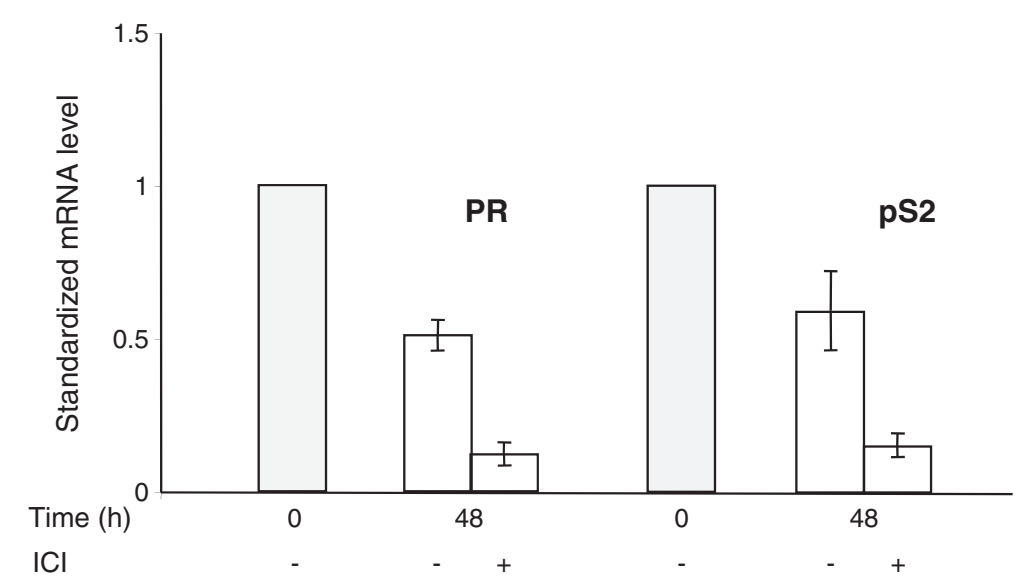

Figure $6 \mathrm{ICI} 182780$ is required for the efficient suppression of ER-dependent endogenous transcripts during serum starvation. Exponentially growing MCF-7 cells (shaded bars) and cells incubated for $48 \mathrm{~h}$ in serum- and phenol red-free medium, with or without ICI 182780 $(10 \mathrm{nM}$ ), were analyzed by RT-QPCR for the ER-inducible pS2 and progesterone receptor (PR) mRNAs. The values of $\Delta \Delta C T$ (means of two independent experiments performed in duplicate) in relation to the exponentially growing cells are presented.

mechanism responsible for ER phosphorylation remains unknown at this moment. As in the case of the basal, constitutive phosphorylation of Akt, it is probably the result of an endogenous process, not requiring added or secreted factors.

\section{Discussion}

"Hormone-dependent" breast cancer cells, by definition, require estrogens for their proliferation. Many experimental models used in the literature employ culture conditions where cells (usually MCF-7, a line mimicking luminal breast cancer) are placed in a medium without phenol red (a weak estrogen) and supplemented with FBS treated with active charcoal to remove serum estrogens. However, the dependence of the MCF-7 cells on estrogens is not absolute and, in such estrogen-free media, these cells continue to proliferate, albeit at a slow rate. Charcoal-stripped FBS contains residual polypeptide growth factors (e.g. IGFs), which can stimulate the proliferation of the MCF-7 cells, but even after $48 \mathrm{~h}$ incubation in serum-free medium, the MCF-7 cells do not become fully quiescent (Figure 3 , time 0 ). To obtain quiescence, the serum starvation medium needs to be supplemented by a "complete" antiestrogen ICI 182780. Even at quiescence, the cellular phosphoSer473-Akt (enzymatically active form, dependent on PI3K signaling) is not completely suppressed. We have verified that serum-deprived MCF-7 cells do not secrete autocrine growth factors capable to activate the PI3K/ Akt pathway.

We analyzed the mechanisms that may drive the residual cell division cycle in estrogen-deprived cells. We also addressed the question of the role of the PI3K/Akt signal in the crosstalk between ER and IGF1R in the G1phase progression.
We observed that unliganded ER continues to act as a transcriptional activator in mitogen-deprived cells, and that this action is blocked by ICI 182780 . This is documented by our data obtained using the MELN cell line derived from the MCF-7 cells by stable transfection with an ERE-TK-Luc construct [28]. The basal expression of the indicator gene in these cells stabilizes at approximately $50 \%$ of the initial level by $48 \mathrm{~h}$ and is not eliminated by long-term estrogen deprivation, but is abruptly blocked by the addition of ICI 182780 .

The activity of the unliganded ER results also in a higher expression of certain cellular genes as compared with that observed when ER activity is cancelled by ICI 182780. This is the case of the PS2 gene, which contains an ERE sequence at its promoter, as well as PR (regulated by atypical half-ERE sequences). A higher expression in serum-starved cells without ICI 182780 is also seen for certain cellular proteins not known as ERtargets. For example, p $21^{\mathrm{WAF} 1 / \mathrm{CIP} 1}$ increases with the time of incubation in serum-free medium when ICI 182780 is omitted. This increase may be an indirect consequence of either the unliganded ER activity during incubation in serum-free medium or of the arrest of the cell cycle (or both). Our laboratory reported earlier that $\mathrm{p} 21^{\mathrm{WAF} 1 / \mathrm{CIP} 1}$ cooperates with the ER in the regulation of the expression of genes, apparently with a preference for those genes that are characteristic of differentiation of the mammary gland cells [18].

The cell content of ER is enhanced when the cells are starved of serum and E2 (Figure 2). The expression of ER-target genes in the absence of agonist ligand may be reinforced by this increase during serum starvation [29].

In contrast, the levels of cyclin D1 protein or mRNA were similar irrespective of the presence or not of ICI 182780 during serum deprivation. The CCND1 gene 

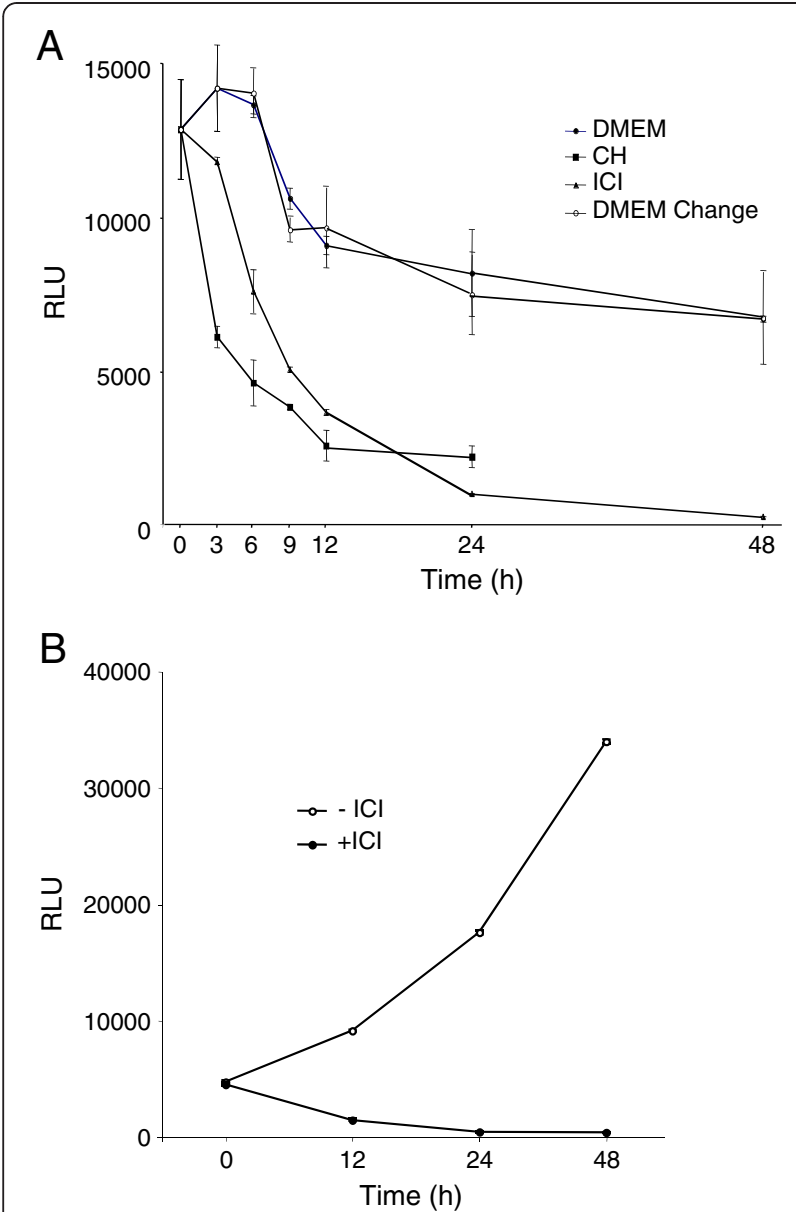

Figure $7 \mathrm{ICI} 182780$ is required for the efficient suppression of ER-dependent luciferase during serum starvation of MELN cells. A. Exponentially growing MELN cells were placed in serum- and phenol red-free medium, with or without ICI 182780 (10 nM) or cycloheximide $(\mathrm{CH} ; 10 \mu \mathrm{g} / \mathrm{mL})$. In a series of dishes, the medium was refreshed at 3, 6, 9, 12 and $24 \mathrm{~h}$. At the times shown, the cells were harvested for the determination of luciferase activity. The results presented are means of duplicates. B. MELN cells were cultivated for more than one month in phenol red-free DMEM supplemented with $5 \%$ charcoal-stripped fetal bovine serum and $100 \mathrm{nM}$ insulin. They were then incubated in phenol red-free DMEM without serum and without insulin, with or without ICI 182780 as indicated. At different time intervals, the cells were harvested for the determination of luciferase activity.

does not contain ERE, and its induction by E2 relies on the action of ER as a transcriptional co-activator [30]. The sustained expression of CCND1 in serum and estrogen-deprived MCF-7 cells results apparently from the activity of other transcription factors [31].

Besides its "canonical" role as a Cdki and its cooperation with ER, p21 ${ }^{\mathrm{WAF} 1 / \mathrm{CIP} 1}$ protein appears also to be involved in the activation of Cdk4 [32]. The elevated expression of $\mathrm{p} 21^{\mathrm{WAF} 1 / \mathrm{CIP} 1}$ could therefore reinforce the mitogenic signaling resulting from the activation of IGF1R in cells not exposed to ICI 182780 .
As we reported earlier, E2 did not rapidly induce Akt phosphorylation [9] (Figure 4) similar observations have been published by others, e.g. [33]. However, the experiments in which we knocked down Akt1 and Akt2 by targeting their shared nucleotide sequence demonstrated that the Akt protein is necessary for the full mitogenic activity of the E2/ER pathway [9]; the present work moreover indicates that the kinase function of Akt is required. Akt2 was more efficient than Akt1, in agreement with the report of Morelli et al. [34]. At the same time, the induction of the PI3K/Akt pathway alone is at best only weakly mitogenic, as illustrated by the weak/ delayed effect of insulin on the cell cycle progression in cells where ER activity is suppressed by ICI 182780 . Note that overexpression of IGF1R may restore the mitogenic activity of IGF [35]. This is in contrast with the fact that stimulation of the cells with insulin was sufficient not only to ensure the direct actions of IGF1R including the phosphorylating activation of Akt (and of its substrate GSK3 $\beta$ resulting in the post-translational actions such as the stabilisation of the cyclin D1 protein), but also the transcriptional activation of CCND1. Our data point to cyclin D1 as the critical element for the estrogen-induced, PI3K/Akt-dependent cell cycle progression. However, cyclin D1 alone is not sufficient to reinitiate the cell cycle progression: cyclin D1 is present in quiescent cells, and, although its level is increased by insulin stimulation (Figures 3 and 5), this is not sufficient for a mitogenic effect [36]. Additional events driven by ER-dependent transcription are necessary. The nature of these additional events is not clear. They do take place in mitogen-deprived cells, albeit at a low rate, due to the transcriptional activity of ligand-free ER and are efficiently blocked by ICI 182780 . Activation of IGF1R has been reported to augment the transcription-promoting activity of the ER [37], at least in part via activation of Akt [34]. ER regulates the transcription of numerous genes involved in cellular functions including cell cycle progression, as well as genes coding for other transcriptional regulators, autocrine/ paracrine factors, and cell survival $[38,39]$. It is plausible that the basal expression of such genes is required for triggering the G1-phase progression, in coordination with an enhanced cellular level of cyclin D1. C-Myc is a candidate for this complementary function of ligand-free ER-dependent transcription as it is induced by insulin in cells starved of serum in the absence but not in the presence of ICI 182780 (Figure 5).

Blocking the PI3K/Akt signaling by LY 294002 led to a strong reduction of the CCND1 transcript, both at quiescence and in mitogen-treated cells. The promoter of the CCND1 gene contains several regulatory elements on which the PI3K/Akt signal can participate. For instance, transcription of CCND1 is inhibited by FOXO 
family transcription factors, which are inactivated by phosphorylation by Akt [40-42] suggesting a mechanism to account for this observation. The effect was selective as, for instance, the expression of the $c-M y c$ gene was not reduced.

We propose that, in order to induce the cell cycle progression in the MCF-7 cells, both the presence of functional Akt kinase and the transcriptional activation by the ER are required (Figure 8). The basal, ligandindependent transcriptional activation of ER is sufficient to complement the mitogenic signaling via IGF1R/PI3K/ Akt; the expression of the $c-M y c$ gene may be part of this mechanism. Conversely, the basal level of phosphoAkt present in the serum- and estrogen-deprived cells, with or without ICI 182780, is sufficient to supply the indispensable activity of the Akt kinase needed for the full mitogenic activity of the E2/ER complex. The basal level of phospho-Akt is a consequence of intracellular processes, not requiring added or secreted (autocrine) factors. The precise mechanism which leads to the basal PI3K/Akt activity is not known. The function of the Akt kinase in the mitogenic signaling may be to maintain a sufficient level of phosphorylation of FOXO transcription factors and of GSK3 $\beta$ in order to ensure the transcription of the CCND1 gene and to stabilize the cyclin D1 protein, necessary for the activation of Cdk4/6 and the primary phosphorylation of $\mathrm{Rb}$. A critical role of cyclin D1 in the breast cancer cell proliferation has been proposed by several laboratories and recently documented in the signaling by anterior gradient-2 [43]. In practical terms, we believe that the development of hormonal therapies based on "full" antiestrogens (lacking agonist action) could improve the outcome of both early and advanced breast cancer. Suppression of estrogen synthesis by the use of aromatase inhibitors is clearly not sufficient to abolish the participation of ligandfree ER in the mitogenic signaling by other growth factors. An additional and substantial improvement

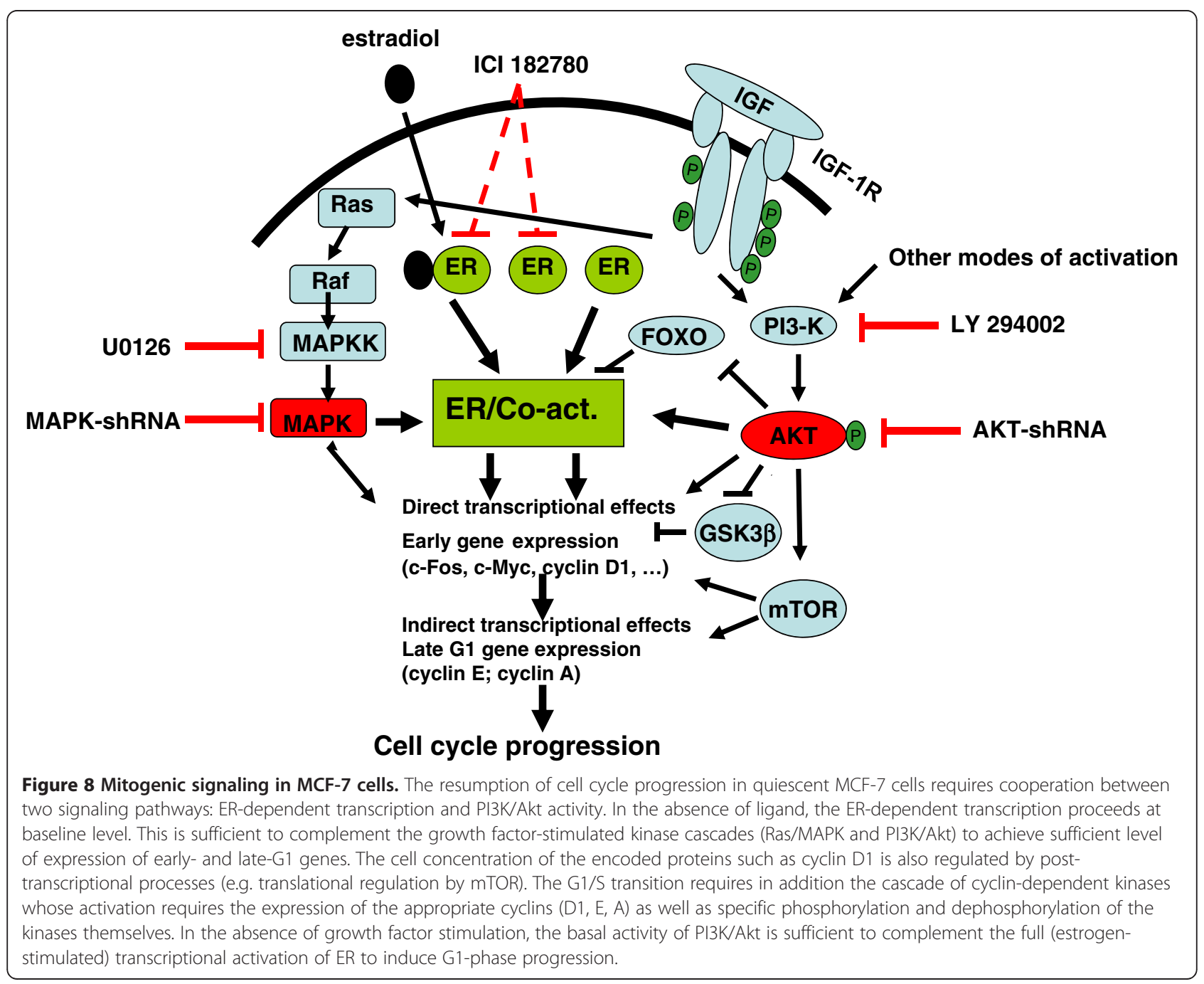


would require simultaneous targeting the PI3K/Akt pathway but, until now, no clinically applicable methods have been reported. Also, while most research addressing the need to complement targeted therapies of breast cancer concentrates on the HER family [44], an alternative approach directed at the IGF1R-dependent signaling deserves attention. The interest of the IGF1R pathway is well understood for the development of targeted therapies in other solid tumors including the basal-like, triple negative breast cancer [45]; there is now ample evidence that this pathway is important also in luminal-type breast cancer and may play a role in the recurrence after endocrine therapy.

\section{Conclusion}

We show that transcriptional activity of the ligand-free estrogen receptor is sufficient to complement the mitogenic action of the IGF1R-induced kinase cascade. Reciprocally, PI3K/Akt activity is required to complement the mitogenic effect of the agonist-activated ER. The basal level of PI3K/Akt present in cells in the absence of exogenous growth factors is sufficient for the full mitogenic effect of estradiol. Thus, both ER and PI3K/Akt need to be targeted for an effective inhibition of the proliferation of hormone-dependent breast cancer cells.

\section{Additional files}

Additional file 1: Figure S1. Knock-down of the Akt signal by shAkt. Transfections were carried out by the Icafectin method (Eurogentec) according to the manufacturer' protocol with the shRNA as indicated. The cells were serum-starved during $48 \mathrm{~h}$ and then harvested and analyzed by Western blotting with the Akt antibody. Actin was used as control.

Additional file 2: Figure S2. $p$ - Akt signal is abolished by phosphatase. The cells were starved as in Figure 2 and then stimulated by addition of insulin (1 mM) for $1 \mathrm{~h}$. The cells were lysed in a buffer without EDTA and proteases inhibitors. Portions of lysates (200 $\mathrm{\mu g}$ of total protein) were incubated with calf intestinal alkaline phosphatase $(0.05 \mathrm{U} / \mathrm{mg}$ protein) for $1 \mathrm{~h}$ at $37^{\circ} \mathrm{C}$. The lysates were analyzed by Western blotting for Phospho Ser473-Akt.

Additional file 3: Figure S3. Serum-deprived MCF-7 cells do not secrete autocrine factors. The cells were made quiescent in medium with ICI 182780 during $48 \mathrm{~h}$. They were then placed for $6 \mathrm{~h}$ in fresh medium (serum- and phenol red-free) with ICI 182780; this was used as conditioned medium (CM). Another series of dishes were stimulated for $1 \mathrm{~h}$ or $3 \mathrm{~h}$ with CM or with insulin as a positive control, lysed and analyzed for phospho-Ser473 Akt

Additional file 4: Figure S4. Cell cycle progression of cells stimulated by insulin or E2. MCF-7 cells were deprived of serum in phenol red-free medium with or without ICl 182780 during $48 \mathrm{~h}$, and then stimulated with insulin or with E2 as described in the text. Cells harvested at the different time points were labeled with propidium iodide and analyzed by flow cytometry. The data were evaluated using the ModFit LT software.

Additional file 5: Figure S5. Akt phosphorylation is equally induced by IGF-I and insulin in cells exposed to ICI 182780. Serum- and E2-starved cells exposed or not to ICI 182780 during $48 \mathrm{~h}$ were stimulated with IGF-I (10 nM) or insulin (1 mM) for $1 \mathrm{~h}$. The lysates were analyzed for phospho- Ser473 Akt.

\section{Abbreviations}

cdk: Cyclin dependent kinase; cdki: Cyclin dependent kinase inhibitory protein; E2: Estradiol; ER: Estrogen receptor; ERE: Estrogen response element; GSK: Glycogen synthase kinase; HER: Human epidermal growth factor receptor; IGF: Insulin-like growth factor; IGF1R: Insulin-like growth factor type 1 receptor; PI3K: Phosphatidyl inositol-3 kinase; SERD: Selective estrogen receptor degrader; SERM: Selective estrogen receptor modulator; shRNA: Short hairpin RNA.

\section{Competing interests}

The authors declare that they have no conflicts of interests concerning this work.

\section{Authors' contributions}

AMG participated at the design, execution and interpretation of the experiments, as well as writing up of the manuscript. MS participated at the RTQPCR experiments and the presentation of the manuscript. MB participated at the cell culture experiments and the presentation of the manuscript. GR participated at the interpretation of the data and the presentation of the manuscript. JM participated at the design, execution and interpretation of the experiments, as well as writing up of the manuscript. All authors read and approved the final manuscript.

\section{Acknowledgements}

We are grateful to Dr. F Czauderna for the shAkt $(1+2)$ vector and to Dr. Xiao G H for the Akt1 and Akt2 expression vectors. We thank Dr. A.M Faussat for analyzing the cells by flow cytometry.

Received: 25 November 2011 Accepted: 26 June 2012 Published: 16 July 2012

\section{References}

1. Burstein $\mathrm{HJ}$, Griggs JJ: Adjuvant hormonal therapy for early-stage breast cancer. Surg Oncol Clin N Am 2010, 19(3):639-647.

2. Janni W, Hepp P: Adjuvant aromatase inhibitor therapy: outcomes and safety. Cancer Treat Rev 2010, 36(3):249-261.

3. Michalides R, Griekspoor A, Balkenende A, Verwoerd D, Janssen L, Jalink K, Floore A, Velds A, van't Veer L, Neefjes J: Tamoxifen resistance by a conformational arrest of the estrogen receptor alpha after PKA activation in breast cancer. Cancer Cell 2004, 5(6):597-605.

4. Di Cosimo S, Baselga J: Targeted therapies in breast cancer: where are we now? Eur J Cancer 2008, 44(18):2781-2790.

5. Massarweh S, Osborne CK, Creighton CJ, Qin L, Tsimelzon A, Huang S, Weiss H, Rimawi M, Schiff R: Tamoxifen resistance in breast tumors is driven by growth factor receptor signaling with repression of classic estrogen receptor genomic function. Cancer Res 2008, 68(3):826-833.

6. Saxena R, Dwivedi A: ErbB family receptor inhibitors as therapeutic agents in breast cancer: current status and future clinical perspective. Med Res Rev 2012, 32(1):166-215.

7. Prall OW, Rogan EM, Musgrove EA, Watts CK, Sutherland RL: c-Myc or cyclin D1 mimics estrogen effects on cyclin E-Cdk2 activation and cell cycle reentry. Mol Cell Biol 1998, 18(8):4499-4508.

8. Castoria G, Migliaccio A, Bilancio A, Di Domenico M, de Falco A, Lombardi M, Fiorentino R, Varricchio L, Barone MV, Auricchio F: PI3-kinase in concert with Src promotes the S-phase entry of oestradiol-stimulated MCF-7 cells. EMBO J 2001, 20(21):6050-6059.

9. Gaben AM, Saucier C, Bedin M, Redeuilh G, Mester J: Mitogenic activity of estrogens in human breast cancer cells does not rely on direct induction of mitogen-activated protein kinase/extracellularly regulated kinase or phosphatidylinositol 3-kinase. Mol Endocrinol 2004, 18(11):2700-2713.

10. Dufourny B, Alblas J, van Teeffelen HA, van Schaik FM, van der Burg B, Steenbergh PH, Sussenbach JS: Mitogenic signaling of insulin-like growth factor I in MCF-7 human breast cancer cells requires phosphatidylinositol 3-kinase and is independent of mitogen-activated protein kinase. J Biol Chem 1997, 272(49):31163-31171.

11. Lai A, Sarcevic B, Prall OW, Sutherland RL: Insulin/insulin-like growth factor-I and estrogen cooperate to stimulate cyclin E-Cdk2 activation and cell Cycle progression in MCF-7 breast cancer cells through differential regulation of cyclin E and p21(WAF1/Cip1). J Biol Chem 2001, 276(28):25823-25833. 
12. Varma H, Conrad SE: Antiestrogen ICI 182,780 decreases proliferation of insulin-like growth factor I (IGF-I)-treated MCF-7 cells without inhibiting IGF-I signaling. Cancer Res 2002, 62(14):3985-3991.

13. Wittmann BM, Sherk A, McDonnell DP: Definition of functionally important mechanistic differences among selective estrogen receptor downregulators. Cancer Res 2007, 67(19):9549-9560.

14. Czauderna F, Fechtner M, Aygun H, Arnold W, Klippel A, Giese K, Kaufmann $\mathrm{J}$ : Functional studies of the $\mathrm{PI}(3)$-kinase signalling pathway employing synthetic and expressed siRNA. Nucleic Acids Res 2003, 31(2):670-682.

15. Xiao GH, Jeffers M, Bellacosa A, Mitsuuchi $Y$, Vande Woude GF, Testa JR: Anti-apoptotic signaling by hepatocyte growth factor/Met via the phosphatidylinositol 3-kinase/Akt and mitogen-activated protein kinase pathways. Proc Natl Acad Sci U S A 2001, 98(1):247-252.

16. Remy I, Montmarquette A, Michnick SW: PKB/Akt modulates TGF-beta signalling through a direct interaction with Smad3. Nat Cell Biol 2004, 6(4):358-365.

17. Henglein B, Chenivesse X, Wang J, Eick D, Brechot C: Structure and cell cycle-regulated transcription of the human cyclin A gene. Proc Natl Acad Sci U S A 1994, 91(12):5490-5494.

18. Fritah A, Saucier C, Mester J, Redeuilh G, Sabbah M: p21WAF1/CIP1 selectively controls the transcriptional activity of estrogen receptor alpha. Mol Cell Biol 2005, 25(6):2419-2430.

19. Conery AR, Cao Y, Thompson EA, Townsend CM Jr, Ko TC, Luo K: Akt interacts directly with Smad3 to regulate the sensitivity to TGF-beta induced apoptosis. Nat Cell Biol 2004, 6(4):366-372.

20. Nakatani K, Thompson DA, Barthel A, Sakaue H, Liu W, Weigel RJ, Roth RA: Up-regulation of Akt3 in estrogen receptor-deficient breast cancers and androgen-independent prostate cancer lines. J Biol Chem 1999, 274 (31):21528-21532.

21. Zinda MJ, Johnson MA, Paul JD, Horn C, Konicek BW, Lu ZH, Sandusky G, Thomas JE, Neubauer BL, Lai MT, et al: AKT-1, -2 , and -3 are expressed in both normal and tumor tissues of the lung, breast, prostate, and colon. Clin Cancer Res 2001, 7(8):2475-2479.

22. Carroll JS, Lynch DK, Swarbrick A, Renoir JM, Sarcevic B, Daly RJ, Musgrove EA, Sutherland RL: p27(Kip1) induces quiescence and growth factor insensitivity in tamoxifen-treated breast cancer cells. Cancer Res 2003, 63(15):4322-4326.

23. Polo ML, Arnoni MV, Riggio M, Wargon V, Lanari C, Novaro V: Responsiveness to PI3K and MEK inhibitors in breast cancer. Use of a 3D culture system to study pathways related to hormone independence in mice. PLoS One 2010, 5(5):e10786

24. Wardell SE, Marks JR, McDonnell DP: The turnover of estrogen receptor alpha by the selective estrogen receptor degrader (SERD) fulvestrant is a saturable process that is not required for antagonist efficacy. Biochem Pharmacol 2011, 82(2):122-130.

25. Rosenwald IB, Setkov NA, Kazakov VN, Chen JJ, Ryazanov AG, London IM, Epifanova Ol: Transient inhibition of protein synthesis induces expression of proto-oncogenes and stimulates resting cells to enter the cell cycle. Cell Prolif 1995, 28(12):631-644.

26. Vinals F, Chambard JC, Pouyssegur J: p70 S6 kinase-mediated protein synthesis is a critical step for vascular endothelial cell proliferation. J Biol Chem 1999, 274(38):26776-26782.

27. Diehl JA, Cheng M, Roussel MF, Sherr CJ: Glycogen synthase kinase-3beta regulates cyclin D1 proteolysis and subcellular localization. Genes Dev 1998, 12(22):3499-3511.

28. Gagne D, Balaguer P, Demirpence E, Chabret C, Trousse F, Nicolas JC, Pons M: Stable luciferase transfected cells for studying steroid receptor biological activity. J Biolumin Chemilumin 1994, 9(3):201-209.

29. Fowler AM, Solodin NM, Valley CC, Alarid ET: Altered target gene regulation controlled by estrogen receptor-alpha concentration. $\mathrm{Mol}$ Endocrinol 2006, 20(2):291-301.

30. Sabbah M, Courilleau D, Mester J, Redeuilh G: Estrogen induction of the cyclin D1 promoter: involvement of a cAMP response-like element. Proc Natl Acad Sci U S A 1999, 96(20):11217-11222.

31. Klein EA, Assoian RK: Transcriptional regulation of the cyclin D1 gene at a glance. J Cell Sci 2008, 121(Pt 23):3853-3857.

32. Dupont J, Karas M, LeRoith D: The cyclin-dependent kinase inhibitor p21CIP/WAF is a positive regulator of insulin-like growth factor I-induced cell proliferation in MCF-7 human breast cancer cells. J Biol Chem 2003, 278(39):37256-37264.
33. Becker MA, Ibrahim YH, Cui X, Lee AV, Yee D: The IGF pathway regulates ERalpha through a S6K1-dependent mechanism in breast cancer cells. Mol Endocrinol 2011, 25(3):516-528.

34. Morelli C, Lanzino M, Garofalo C, Maris P, Brunelli E, Casaburi I, Catalano S, Bruno R, Sisci D, Ando S: Akt2 inhibition enables the forkhead transcription factor FoxO3a to have a repressive role in estrogen receptor alpha transcriptional activity in breast cancer cells. Mol Cell Biol 2010, 30(3):857-870

35. Zhang Y, Moerkens M, Ramaiahgari S, de Bont H, Price L, Meerman J, van de Water B: Elevated insulin-like growth factor 1 receptor signaling induces antiestrogen resistance through the MAPK/ERK and PI3K/Akt signaling routes. Breast Cancer Res BCR 2011, 13(3):R52.

36. Mawson A, Lai A, Carroll JS, Sergio CM, Mitchell CJ, Sarcevic B: Estrogen and insulin/IGF-1 cooperatively stimulate cell cycle progression in MCF-7 breast cancer cells through differential regulation of c-Myc and cyclin D1. Mol Cell Endocrinol 2005, 229(1-2):161-173.

37. Lee AV, Weng CN, Jackson JG, Yee D: Activation of estrogen receptormediated gene transcription by IGF-I in human breast cancer cells. J Endocrinol 1997, 152(1):39-47.

38. Charpentier AH, Bednarek AK, Daniel RL, Hawkins KA, Laflin KJ, Gaddis S, MacLeod MC, Aldaz CM: Effects of estrogen on global gene expression: identification of novel targets of estrogen action. Cancer Res 2000, 60(21):5977-5983.

39. Frasor J, Danes JM, Komm B, Chang KC, Lyttle CR, Katzenellenbogen BS: Profiling of estrogen up- and down-regulated gene expression in human breast cancer cells: insights into gene networks and pathways underlying estrogenic control of proliferation and cell phenotype. Endocrinology 2003, 144(10):4562-4574.

40. Reagan-Shaw S, Ahmad N: RNA interference-mediated depletion of phosphoinositide 3-kinase activates forkhead box class $\mathrm{O}$ transcription factors and induces cell cycle arrest and apoptosis in breast carcinoma cells. Cancer Res 2006, 66(2):1062-1069.

41. Burgering BM: A brief introduction to FOXOlogy. Oncogene 2008, 27 (16):2258-2262.

42. Zou Y, Tsai WB, Cheng CJ, Hsu C, Chung YM, Li PC, Lin SH, Hu MC: Forkhead box transcription factor FOXO3a suppresses estrogendependent breast cancer cell proliferation and tumorigenesis. Breast Cancer Res 2008, 10(1):R21.

43. Vanderlaag KE, Hudak S, Bald L, Fayadat-Dilman L, Sathe M, Grein J, Janatpour MJ: Anterior gradient-2 plays a critical role in breast cancer cell growth and survival by modulating cyclin D1, estrogen receptor-alpha and survivin. Breast Cancer Res BCR 2010, 12(3):R32.

44. Johnston SR: New strategies in estrogen receptor-positive breast cancer. Clin Cancer Res 2010, 16(7):1979-1987.

45. Klinakis A, Szabolcs M, Chen G, Xuan S, Hibshoosh H, Efstratiadis A: Igf1r as a therapeutic target in a mouse model of basal-like breast cancer. Proc Natl Acad Sci U S A 2009, 106(7):2359-2364.

doi:10.1186/1471-2407-12-291

Cite this article as: Gaben et al:: Ligand-free estrogen receptor activity complements IGF1R to induce the proliferation of the MCF-7 breast cancer cells. BMC Cancer 2012 12:291.

\section{Submit your next manuscript to BioMed Central and take full advantage of:}

- Convenient online submission

- Thorough peer review

- No space constraints or color figure charges

- Immediate publication on acceptance

- Inclusion in PubMed, CAS, Scopus and Google Scholar

- Research which is freely available for redistribution 